\title{
No-fault compensation for medical accidents
}

\author{
${ }^{1} \mathrm{KM}$ Norrie, ${ }^{2} \mathrm{RA}$ Hendry \\ ${ }^{1}$ Professor, School of Law, University of Strathclyde, Glasgow, UK; ${ }^{2}$ Deputy Medical Director, Medical Protection Society, London, UK
}

KEYWORDS Medical accidents, negligence, compensation, no-fault scheme

Correspondence to K Norrie, School of Law, University of DECLARATION OF INTERESTS No conflict of interests declared.

Medical practice, like any other human activity, sometimes leads to accidents, or unusual complications, or unexpected results. Usually no one is to blame; sometimes someone is at fault. If the patient has been harmed, and the doctor's act (or failure to act) amounts to what the law calls 'negligence', then the patient may seek monetary compensation for the injury they have suffered. Yet any patient who emerges from medical treatment with an injury he or she did not have before the treatment needs care for that injury, whether or not the doctor was negligent, or the negligence caused the injury, or the patient can prove negligence and causation to a sufficient legal standard. The current system of compensation provides high levels of compensation for some patients injured in the course of medical treatment, and no compensation at all for most.

In order to address this inequity, in June 2009 the Scottish Government set up a No-Fault Compensation Review Group (NFCRG), under the Chairmanship of Professor Sheila McLean of Glasgow University, to explore the implications of putting compensation for medical accidents onto a no-fault basis. In November 2010 the Group, of which both authors were members, recommended that a no-fault scheme had significant merits and should be considered by the Scottish Government. In February 2011 the Government accepted this recommendation and indicated that it would commence working out how such a scheme could be implemented. (The papers may be found at: http://www.scotland.gov.uk/Topics/Health/NHSScotland/No-faultCompensation.)

\section{EXISTING NO-FAULT COMPENSATION SCHEMES}

No-fault compensation is neither new nor untried in this country. We already have no-fault schemes covering road traffic accidents and accidents at work, achieved by means of compulsory liability insurance (Road Traffic Act 1988, s.143 and Employers' Liability [Compulsory Insurance] Act 1969). Personal injuries caused by crimes of violence are compensated under the Criminal Injuries Compensation Scheme (Criminal Injuries Compensation Act 1995). Likewise, various social security benefits are in effect no-fault compensation schemes, such as the Industrial Injuries Disablement Benefit, the Armed Forces Compensation Scheme, and the Diffuse Mesothelioma Scheme. The Vaccine Damage Payments Scheme (Vaccine Damage Payments Act 1979) provides lump sums to young children who suffer serious adverse consequences (mental and/or physical) as a result of being vaccinated against a set list of diseases.

The question then, ultimately a political one, is whether injuries suffered in the course of medical treatment ought to join this list, and if so, how the scheme is to be administered.

\section{JUSTIFICATIONS FOR NO-FAULT COMPENSATION}

To treat medical accidents differently from most other accidents is justified only if the operation of the existing compensation system is particularly inappropriate in medical cases. The NFCRG considered that this was so for the following reasons:

- The legal test for fault is far removed from moral fault: the law currently focuses on causes and not effects and gives no ethical ground for identifying who deserves to be compensated.

- Liability is often completely out of proportion to the level of fault: a moment of carelessness by an obstetrician, for example, might lead to massive and long-term disability.

- There is a risk that the present law encourages medical decisions to be made on the basis of reducing the chances of litigation rather than on a professional judgement of what is best for patients.

- Learning from mistakes is made more difficult if admitting one's own errors might lead to liability.

- When someone is ill, they feel obliged to seek treatment and they do not have the choices that they typically have in other walks of life of whether to undertake risks or not. Self-help is seldom, if ever, an option.

- The legal process is particularly complex in medical negligence claims: the test for professional liability is higher than for 'ordinary' liability; the need to find professional witnesses is troublesome; causation within the law of negligence is especially difficult for 
patients to prove; there is seldom an 'equality of arms' between a patient and a healthcare provider. Not only does this reduce the chances of successful claims, but it massively increases the overall costs of legal claims - the law of negligence, in other words, is a highly cost-ineffective means of providing compensation to patients injured during healthcare.

- Presently, compensation paid for out of National Health Service (NHS) funds is assessed on the costs of private treatment and so the existing system affects a shift of resources from public to private providers.

More generally, a system of social healthcare, such as the $\mathrm{NHS}$, is a system based on the understanding that health is a social responsibility. It follows that when something goes wrong it is society, or the state, that should bear the cost. Putting it differently, everyone benefits if we are healthy and so everyone should share the cost of injury in a caring society.

\section{POSSIBLE MODELS}

If no-fault compensation is considered to be particularly appropriate for medical accidents, the next question becomes how this is to be achieved, and the NFCRG reviewed the position in a number of countries around the world, which already provide no-fault compensation in this area.

Most of the Scandinavian countries, for example, deal with medical injuries by means of compulsory insurance. Compensation is paid not to those who suffer injury by negligence but to those whose injuries were 'avoidable', though Denmark also allows claims if injury is unusual and particularly serious; in Norway the test is whether the patient can be expected to have accepted the risk of the bad outcome in advance.

The most radical approach is that adopted by $\mathrm{New}$ Zealand, which has a comprehensive system of accident compensation not limited to medical accidents, run by a state body, the Accident Compensation Corporation. Within the medical field, any personal injury caused by 'treatment injury' is covered, subject to certain specified exceptions, such as mental injuries and 'wrongful birth'.

Some US states, such as Virginia and Florida, provide no-fault compensation but only for birth-related neurological injuries. Hospitals and physicians contribute to a state-run fund and in return they are shielded from litigation in respect of such injuries.

\section{DRAWBACKS OF NO-FAULT SCHEMES}

It has to be recognised, however, that there are some serious drawbacks to any no-fault scheme, for example:

- Compensation is likely to be lower than would be obtained under a normal claim for negligence: in cases of extreme injury this reduction will be very great.
- Removal of the threat of litigation removes an incentive to seek higher standards of care. The link between paying compensation and learning lessons from bad outcomes is broken.

- Compensation is often not what patients want, which is explanation, or apology, and systems improvement, so that the bad outcome does not affect other patients in the future.

- Patients may feel a lack of accountability because the health professional is not financially liable and may therefore look to other bodies such as the General Medical Council or other regulators to hold the professionals to account.

- Causation is often the most difficult element in a claim for negligence, yet it cannot be avoided and so the practical benefits of a no-fault scheme are less than might appear at first sight. Nor is there any real ethical improvement in the operation of a compensation scheme: a person born congenitally injured continues to get nothing from a no-fault compensation scheme though his or her needs are identical to those of a person who suffers the same injury caused by medical treatment that goes wrong.

\section{OTHER QUESTIONS}

Even if it is adjudged that a no-fault scheme has more benefits than disadvantages, there is a host of questions that need political and legal answers. First and most obviously, who pays and how? If an insurance-based model is adopted, is this to be a state-run nationalised body (as in New Zealand) or is it to be open to private insurers (as in Scandinavia)? Should the system operate as an expanded social security claim? Should court action be prohibited, or allowed only when claims for no-fault compensation are rejected? What appeal mechanisms ought there to be? Should there be financial limits on what can be claimed, and if so how much? Are there types of injury that should be excluded (for example mental injuries, or economic injuries beyond loss of earnings)? Should a no-fault scheme be limited to injuries sustained while receiving NHS treatment, or should it also cover private medicine? And what should be the limits of 'medical injury' - does it cover quasimedics and paramedics such as dentists, opticians, chiropodists, physiotherapists, grief-counsellors?

Much work remains to be done and the Scottish Government has indicated their intention to consult with all interested parties as they move forward with this project. It is to be hoped that the professional bodies directly involved fully engage with this process to ensure that any no-fault compensation scheme actually achieves the results that it is aiming for. 